"Managing the equity risk using Short Put Ladder strategy by barrier options"

\begin{tabular}{|c|c|}
\hline AUTHORS & $\begin{array}{l}\text { Monika Timková ĐD https://orcid.org/0000-0002-5774-3230 } \\
\text { Michal Šoltés ĐD https://orcid.org/0000-0002-1421-7177 }\end{array}$ \\
\hline ARTICLE INFO & $\begin{array}{l}\text { Monika Timková and Michal Šoltés (2019). Managing the equity risk using Short } \\
\text { Put Ladder strategy by barrier options. Investment Management and Financial } \\
\text { Innovations, 16(4), 133-145. doi:10.21511/imfi.16(4).2019.12 }\end{array}$ \\
\hline DOI & http://dx.doi.org/10.21511/imfi.16(4).2019.12 \\
\hline RELEASED ON & Tuesday, 03 December 2019 \\
\hline RECEIVED ON & Monday, 21 October 2019 \\
\hline \multirow[t]{2}{*}{ ACCEPTED ON } & Wednesday, 20 November 2019 \\
\hline & \begin{tabular}{|l|l|}
$(c))$ EY \\
\end{tabular} \\
\hline LICENSE & $\begin{array}{l}\text { This work is licensed under a Creative Commons Attribution } 4.0 \text { International } \\
\text { License }\end{array}$ \\
\hline JOURNAL & "Investment Management and Financial Innovations" \\
\hline ISSN PRINT & $1810-4967$ \\
\hline ISSN ONLINE & $1812-9358$ \\
\hline PUBLISHER & LLC "Consulting Publishing Company "Business Perspectives" \\
\hline FOUNDER & LLC "Consulting Publishing Company "Business Perspectives" \\
\hline
\end{tabular}

NUMBER OF REFERENCES

30

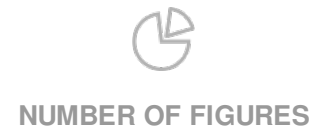

2
NUMBER OF TABLES

11

(C) The author(s) 2023. This publication is an open access article. 


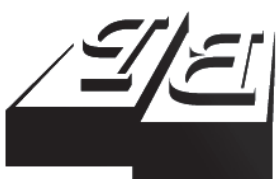

BUSINESS PERSPECTIVES

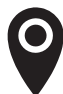

LLC "CPC "Business Perspectives" Hryhorii Skovoroda lane, 10, Sumy, 40022, Ukraine

www.businessperspectives.org

Received on: $21^{\text {st }}$ of October, 2019 Accepted on: 20 $0^{\text {th }}$ of November, 2019

(C) Monika Timková,

Michal Šoltés, 2019

Monika Timková, Ph.D., Assistant Professor, Technical University of Košice, Faculty of Economics, Košice, Slovakia.

Michal Šoltés, Ph.D., Associate Professor, Technical University of Košice, Faculty of Economics, Košice, Slovakia.

\section{MANAGING THE EQUITY RISK USING SHORT PUT LADDER STRATEGY BY BARRIER OPTIONS}

\begin{abstract}
The main aim of the paper is to measure hedging efficiency using the Short Put Ladder strategy formed by barrier options in the equity market. The researchers hedge full protection against price's drop, combining the European down and knock-in put options with the lowest exercise price and vanilla or barrier put options with the higher exercise prices. The authors chose the analyzed alternatives according to the requirement of the zero-cost strategy. The aim of the investigated hedging variants is to secure the minimum constant selling price for the underlying asset's price drop. Theoretical results of this approach were applied in the equity market, i.e., SPDR S\&P 500 ETF. The authors analyzed and compared all hedging variants to each other, however, only the selected techniques were presented in the paper. The findings reveal that the barrier options used for managing the equity risk produce significant reductions of that risk. The right combination of options with the strike prices and the barrier levels wisely selected plays a significant role in risk elimination. Finally, according to the findings, the recommendations for potential investors are introduced.
\end{abstract}

Keywords underlying asset, barrier option, equity option, option strategy, risk management

\section{JEL Classification G11, G13, G32}

\section{INTRODUCTION}

During the past decade, there has been an extraordinary development and expansion of financial derivatives. New financial risks have arisen due to the changes in financial conditions that are related with development in the financial market and the use of individual financial market instruments. Negative impacts on individual business may be eliminated by several means, such as hedging using the financial derivatives. Such instruments enhance the ability to identify and transfer the risk to those investors who are most able and willing to take it.

The paper aims to introduce the contemporary practical methods for managing the equity risk, using the barrier option strategies (Short Put Ladder). The aim is not to avoid a price decrease but only to hedge the minimum acceptable selling price, where it limits your loss to a known amount. The contribution of the paper is the development of 113 hedging variants by barrier and vanilla options, where 64 variants are only with the barrier options and 49 variants in combination with the vanilla options. We hedge full protection against negative movement of underlying assets (UA) price by Down and in (DI) put options with the lowest exercise price and other types of vanilla/barrier put options. Twenty-five hedging variants fulfil this condition. The paper presents only those hedging variants with the highest secured selling price in case of UA's price drop. The results are applied in equity market, specifically, SPDR S\&P 500 ETF. However, this research can be applied for other assets as well. In addition, the advantages and the 
disadvantages of the given strategies are presented related to the use of equity derivative instruments. Finally, a comparative analysis with making and showing the best variant used in the hedging was done. It is necessary to determine the best combination of the strike prices that provides the best opportunity. In the paper, only European options are used, but this approach can be adopted with American options as well. We do not consider any margin requirements, taxes, and execution costs, commission costs, and other possible factors.

\section{LITERATURE REVIEW}

Most investors who hedge use derivatives. Chance and Brooks (2012) define the derivatives as financial instruments, returns of which are derived from other financial tools, referred to as the underlying asset (henceforth, UA). It means that their performance depends on how other financial instruments perform. They are, actually, the most modern instruments suitable for managing the market risk, including interest rate risk, equity risk, commodity risk, and foreign exchange risk. Among the wide range of financial derivatives used to manage the equity risk, in this paper, we focus on equity options. Equity options are one of the best ways for corporations or individuals to hedge against negative movements in equity price. According to Chorafas (2006), equity options are the most common type of equity derivatives. Option is an agreement between a buyer and a seller that gives the buyer the right (no obligation) to buy (call option, henceforth referred to as $\mathrm{CO}$ ) or sell (put option, henceforth, referred to as PO) financial asset at a specified maturity date at a price agreed upon today (the exercise price or strike price). For this right, the buyer pays the seller the amount of money called the premium. According to Allen (2013), a barrier option is a modification of a standard call or put option where the payoff depends only on fulfilling the condition that the given price level (referred as the barrier) has been reached or not during certain time period. The barrier level can be set below (DOWN) or above (UP) the UA's price at the time of writing the option and the right to exercise the option appears (IN) or disappears (OUT) at the given barrier level. In total, there are 4 types of barrier options, i.e., UI, UO, DI, DO call/put options. Barrier options are generally cheaper than standard vanilla options due to the barrier level (Zhang, 1998). As we will see later, DI put options with the combinations of vanilla/barrier put options are the best variants for drop hedging. One of the advantages of options is that they can be used to create a very wide range of payoff patterns, which are called option strategies. Therefore, the methodology of the paper is based on option strategies. More information about option strategies is introduced in Cohen (2005), Kakushadze and Serur (2018).

Nowadays, the methods and instruments used to manage the equity risk are more complex. According to Carol (2008), hedging is a risk management technique that minimizes or even eliminates the impact of a possible change in a particular risk factor on the investment value. This is realized through targeted purchases and sales of financial instruments designed to ensure the risk. To avoid making a loss in the spot market, the investor decides to hedge the position. In order to hedge the position in the spot market, we simply have to take a counter position in the derivatives market. Since the position in the spot is long, we hedge for short in the futures market. In this case, the maximum loss is the premium we paid. Over the years, many financial studies have dealt with the risk management using the financial derivatives. Brown (2001), Zhou and Wang (2013) investigated the foreign exchange risk management through derivatives. Pineda and Conejo (2012) introduced electricity derivatives, including the options in managing the financial risks. Also, banks use credit derivatives for hedging their risk, as it was showed by Deng, Elyasiani, and Mao (2017) or Hirtle (2009). Hammoudeh and McAleer (2013) published an overview of financial derivatives and their use in optimal portfolio management. Hankins (2009) dealt with managing the risk in firms, where he examined the interactions between operational and financial hedging. On the other hand, Loss (2012) investigated how interactions between firms affect their hedging strategies. Managing the price risk using Short Put Ladder strategy by vanilla options an agriculture is introduced by Harčariková (2018). Short Call Ladder strategy and its use in hedging in energy sector is 
examined by Harčariková and Šoltés (2016), where all possible ways are presented.

Nevertheless, research on managing the risk using the barrier options has not been dealt so far and therefore appears to be unique. The aim is to show the way how to minimize the risk that the UA's price falls. Hence, comparing the various equity risk managing variants using Short Put Ladder option strategy created by barrier options fills a noticeable gap in this field. Our theoretical results of the risk management using the barrier options can contribute to the literature in several ways. In addition, the research may give some insights for practitioner audiences and also for the research or academic community.

\section{METHODOLOGY}

The research paper introduces the option strategies and their usage in risk management. Options and option strategies play the important role in financial engineering. These instruments can be used in the design of innovative financial products proved by Hull (2017) and in the risk management showed by Terje (2016). The methodology of the paper is based on these instruments strengthening the significant role of options valuation. Therefore, understanding of Short Put Ladder strategy (henceforth, SPL) is critical for the right usage in risk management. SPL is formed by purchasing $n$ PO with the exercise price $X_{1}$, the premium $p_{1 B}$ per option, by purchasing $n \mathrm{PO}$ with a higher exercise price $X_{2}$, the premium $p_{2 B}$ per option and by selling $n$ PO with the highest exercise price $X_{3}$, the premium $p_{3 S}$ per option (Šoltés \& Amaitiek, 2010) at the same time. The introduced strategy can be formed without initial costs, i.e., received option premiums are higher than total paid option premiums, i.e.,

$$
n \cdot p_{3 S}>n \cdot\left(p_{1 B}+p_{2 B}\right) \text {. }
$$

As it is proved, the higher the exercise price, the higher the put option premium. In our research, only European options are considered for the same UA and with the same maturity date. Many studies have dealt with risk management using the options and option strategies (based on vanilla and barrier options). Hedging against price increase is showed by Amaitiek, Bálint, and Rešovský (2010) and against price decrease by Šoltés and Rusnáková (2013). Based on these studies, all possible ways of SPL strategy design are analyzed by combinations of vanilla and barrier options with the purpose for drop hedging.

In this case, we consider all 113 variants of SPL strategy creation based on barrier options. The paper presents only those variants, which hedge the highest selling price. Full hedging against price drop is possible only using DI PO with the lowest exercise price. In this case, all combinations of DI PO together with two various put and put barrier options are analyzed. There are 9 ways with the vanilla options and 16 ways only with barrier options possible to create. The selected secured ways have to fulfil the zero-cost conditions. We apply theoretical results to the SPDR S\&P 500 ETF. We also evaluate hedger's selling price at the maturity date, compare the proposed hedging variants and give the recommendations for potential investors.

The analysis is based on the value of European vanilla and barrier options on the SPY with the various exercise prices and the barrier levels selected by the authors. We gain the data on the real vanilla options from Yahoo Finance (2018). However, European barrier option prices are not accessible for public; therefore, we have to calculate their prices. The methodology of the paper is based on Black and Scholes (1973) in vanilla option pricing and Merton (1973) in European DO CO option pricing. Rubinstein and Reiner (1991) derived the formulae for 8 types of the barrier options. Finally, Haug (2007) applied the valuation formulae on all 16 types of European barrier options.

According to this model, we use the following input parameters:

- the actual UA' spot price $S_{0}$;

- the exercise price $X$;

- the barrier $B$;

- the risk-free interest rate $r$ (U.S. Treasury rate, www.bloomberg.com);

- the implied volatility $\sigma$ (based on historical volatility);

- $\quad$ the dividend yield $q$;

- the time to maturity $t$. 
Our calculations of standard European barrier call/put option prices are based right on this model while all the selected barrier options are processed in the statistical program $\mathrm{R}$ (package fExoticOptions) by the following function (Iacus, 2011):

BarrierOption $\left(\begin{array}{l}\text { barrType, type, } \\ \text { underlying, strike, } \\ \text { dividendYield, } \\ \text { riskFreeRate, } \\ \text { maturity, volatility, } \\ \text { barrier }\end{array}\right)$.

\section{ANALYSIS OF THE HEDGING TECHNIQUES BASED ON BARRIER OPTIONS}

Let us suppose that the firm decides to hedge by using SPL option strategy. Let us create the strategy by purchasing $n$ PO with the exercise price $X_{1}$ and at the same time by purchasing $n \mathrm{PO}$ with the exercise price $X_{2}$ and by selling $n$ PO with the exercise price $X_{3}$ on the same stock. The exercise prices should be set as $X_{1}<X_{2}<X_{3}$. In the analysis of hedging techniques, different levels of barriers are considered (see Table 1). Based on our approach, we assume the same level of lower $D$ (for DI and DO barrier options) and upper $U$ (for UI and UO barrier options) barriers for investigated hedging variants. In case of DI/DO put options, the barrier $D$ must be set lower than the strike price; otherwise, it is correspondent to classical vanilla put options. For UI/UO CO, the barrier $U$ should be set lower, equal, or higher than the strike price.

Let us consider that the firm is planning to sell $n$ pieces of the selected UA from its portfolio. The firm also expects that market goes turbulent and the UA's price is going to drop in the future. Considering the unsecure position, the income from the future sale of $n$ pieces of stocks at time $T$ is $n \cdot S_{T}$, where $S_{T}$ is the UA's spot price at time $T$.

In total, we can create 113 hedging variants using the combinations of barrier and vanilla options, out of which 64 variants are only with barrier options and 49 variants are in combination with vanilla options. In case of UA's price drop, the firm must use DI put options with the lowest strike price to achieve fully secured position. In this case, 25 variants fulfill the condition of full hedging. Rusnáková (2012) presents all relations for analytical expressions of vanilla and barrier options used in our approach. In the following part, selected hedging variants with incomes for asset's price drop are introduced. It is valid that the maturity date has to be the same for all options used. Let us construct the SPL strategy by buying $n$ DI PO with the exercise price $X_{1}$, the premium $p_{1 B D I}$ per option, the barrier level $D$ and at the same time by buying the same amount of $n \mathrm{PO}$ with the higher exercise price $X_{2}$, the premium $p_{2 B}$ per option and by selling $n$ PO with the highest exercise price $X_{3}$, the premium $p_{3 S}$ per option. Table 2 shows the final hedged selling price of SPL option strategy_1 as a sum the cash market price and the future market payoff.

Based on Table 2, which shows the comparison of cash market price and final hedged selling price, we can conclude that the expectations of reaching the lower barrier $D$ by underlying asset during time to maturity and $S_{T}<X_{1}$ at the maturity date is desired. In this scenario, the income from final selling price is constant in amount of $n \cdot\left(X_{1}+X_{2}-X_{3}-p_{1 B D I}-p_{2 B}+p_{3 S}\right)$. By comparing with the cash market price (the unsecured position), theincome will behigher for hedged strategy if $S_{T} \leq n \cdot\left(X_{1}+X_{2}-X_{3}-p_{1 B D I}-p_{2 B}+p_{3 S}\right)$.

Another variant considered is buying $n$ DI PO

Table 1. Put barrier options

Source: Own design.

\begin{tabular}{|c|c|c|c|c|}
\hline Type of put barrier option & Down and in (DI) & Down and out (DO) & Up and in (UI) & Up and out (UO) \\
\hline \multirow[t]{2}{*}{ Barriers } & & $\leqslant x$ & $U<X_{2} \vee U<X_{3}$ & $\begin{array}{l}U=X_{2} \vee U=X_{3} \\
U>X_{2} \vee U>X_{3}\end{array}$ \\
\hline & & $S$ & \multicolumn{2}{|c|}{$U>S$} \\
\hline
\end{tabular}

Notes: $X$ - strike price, $D$ - lower barrier, $U$ - upper barrier. 
Table 2. Final hedged selling prices using Short Put Ladder option strategy_1

Source: Own design.

\begin{tabular}{|c|c|c|c|}
\hline Stock price range & $\begin{array}{c}\text { Cash } \\
\text { market } \\
\text { price }\end{array}$ & Future market payoff & Final hedged selling price \\
\hline $\min _{0 \leq t \leq T}\left(S_{t}\right)>D \wedge S_{T}<X_{1}$ & $n \cdot S_{T}$ & $n \cdot\left(X_{2}-X_{3}-p_{1 B D I}-p_{2 B}+p_{3 S}\right)$ & $n \cdot\left(S_{T}+X_{2}-X_{3}-p_{1 B D I}-p_{2 B}+p_{3 S}\right)$ \\
\hline $\min _{0 \leq t \leq T}\left(S_{t}\right) \leq D \wedge S_{T}<X_{1}$ & $n \cdot S_{T}$ & $-n \cdot\left(S_{T}-X_{1}-X_{2}+X_{3}+p_{1 B D I}+p_{2 B}-p_{3 S}\right)$ & $n \cdot\left(X_{1}+X_{2}-X_{3}-p_{1 B D I}-p_{2 B}+p_{3 S}\right)$ \\
\hline$X_{1} \leq S_{T}<X_{2}$ & $n \cdot S_{T}$ & $n \cdot\left(X_{2}-X_{3}-p_{1 B D I}-p_{2 B}+p_{3 S}\right)$ & $n \cdot\left(S_{T}+X_{2}-X_{3}-p_{1 B D I}-p_{2 B}+p_{3 S}\right)$ \\
\hline$X_{2} \leq S_{T}<X_{3}$ & $n \cdot S_{T}$ & $n \cdot\left(S_{T}-X_{3}-p_{1 B D I}-p_{2 B}+p_{3 S}\right)$ & $n \cdot\left(2 S_{T}-X_{3}-p_{1 B D I}-p_{2 B}+p_{3 S}\right)$ \\
\hline$S_{T} \geq X_{3}$ & $n \cdot S_{T}$ & $-n \cdot\left(p_{1 B D I}+p_{2 B}-p_{3 S}\right)$ & $n \cdot\left(S_{T}-p_{1 B D I}-p_{2 B}+p_{3 S}\right)$ \\
\hline
\end{tabular}

with the exercise price $X_{1}$, the premium $p_{1 B D I}$ per option, the barrier level $D$ and at the same time by buying $n$ put barrier options with the exercise price $X_{2}$, where the put barrier options can be:

- 2A) DI PO with the barrier $D$, i.e., $D<X_{2}$ and premium $p_{2 B D I}$ per option;

- 3B) UI PO with the barrier $U$, i.e., $U>X_{2}$ and premium $p_{2 B U I}$ per option;

- 3C) UO PO with the barrier $U$, i.e., $U>X_{2}$ and premium $p_{2 B U O}$ per option,

and by selling the same amount of PO with the exercise price $X_{3}$, the premium $p_{35}$ per option. Tables 3 and 4 show the final hedged selling prices of SPL option strategy_2 and 3.

Finally, we consider variant designed by buying $n$ DI PO with the exercise price $X_{1}$, the premium $p_{1 B D I}$ per option, the barrier level $D$ and at the same time by buying $n$ put barrier options with the exercise price $X_{2}$, where the put barrier options can be:
- $\quad 4 \mathrm{~A}) \mathrm{UI} P O$ with the barrier U, i.e., $U>X_{2}$ and premium $p_{2 B U I}$ per option;

- 4B) UO PO with the barrier U, i.e., $U>X_{2}$ and premium $p_{2 B U O}$ per option,

- $\quad$ and by selling the same amount of $n$ DI PO with the exercise price $X_{3}$, the premium $\mathrm{p}_{3 S D I}$ per option and the barrier $D$. Table 5 shows the final hedged selling prices of SPL_4 for put barrier options used.

Investor's decision depends on choosing the put barrier options (DI, DO, UI, UO) regarding the type of expectations of UA's price development. We can predict strong/slow drop or strong/slow increase of the UA. According to this, the put barrier options are chosen to the hedging. Some options secure the final selling price only partially (DO, UO, UI put options for the strike price $X_{1}$ ), other types fully (DI put option for the strike price $X_{1}$ ). Finally, it may not be a perfect hedge, but it should remove much of the risk and the hedger has to make a final decision.

Table 3. Final hedged selling prices using Short Put Ladder option strategy_2A

Source: Own design.

\begin{tabular}{c|c}
\hline Stock price range & Final hedged selling price_2A \\
\hline $\min _{0 \leq t \leq T}\left(S_{t}\right)>D \wedge S_{T}<X_{1}$ & $n \cdot\left(2 S_{T}-X_{3}-p_{1 B D I}-p_{2 B D I}+p_{3 S}\right)$ \\
$\min _{0 \leq t \leq T}\left(S_{t}\right) \leq D \wedge S_{T}<X_{1}$ & $n \cdot\left(X_{1}+X_{2}-X_{3}-p_{1 B D I}-p_{2 B D I}+p_{3 S}\right)$ \\
$\min _{0 \leq t \leq T}\left(S_{t}\right)>D \wedge X_{1} \leq S_{T}<X_{2}$ & $n \cdot\left(2 S_{T}-X_{3}-p_{1 B D I}-p_{2 B D I}+p_{3 S}\right)$ \\
$\min _{0 \leq t \leq T}\left(S_{t}\right) \leq D \wedge X_{1} \leq S_{T}<X_{2}$ & $n \cdot\left(S_{T}+X_{2}-X_{3}-p_{1 B D I}-p_{2 B D I}+p_{3 S}\right)$ \\
$X_{2} \leq S_{T}<X_{3}$ & $n \cdot\left(2 S_{T}-X_{3}-p_{1 B D I}-p_{2 B D I}+p_{3 S}\right)$ \\
$S_{T} \geq X_{3}$ & $n \cdot\left(S_{T}-p_{1 B D I}-p_{2 B D I}+p_{3 S}\right)$ \\
\hline
\end{tabular}


Table 4. Final hedged selling prices using Short Put Ladder option strategy_3

Source: Own design.

\begin{tabular}{c:c:c}
\hline Stock price range & Final hedged selling price_3A & Final hedged selling price_3B \\
\hline $\min _{0 \leq t \leq T}\left(S_{t}\right)>D \wedge \max _{0 \leq t \leq T}\left(S_{t}\right)<U \wedge S_{T}<X_{1}$ & $n \cdot\left(2 S_{T}-X_{3}-p_{1 B D I}-p_{2 B U I}+p_{3 S}\right)$ & $n \cdot\left(S_{T}+X_{2}-X_{3}-p_{1 B D I}-p_{2 B U O}+p_{3 S}\right)$ \\
\hdashline $\min _{0 \leq t \leq T}\left(S_{t}\right) \leq D \wedge \max _{0 \leq t \leq T}\left(S_{t}\right)<U \wedge S_{T}<X_{1}$ & $n \cdot\left(S_{T}+X_{1}-X_{3}-p_{1 B D I}-p_{2 B U I}+p_{3 S}\right)$ & $n \cdot\left(X_{1}+X_{2}-X_{3}-p_{1 B D I}-p_{2 B U O}+p_{3 S}\right)$ \\
$\min _{0 \leq t \leq T}\left(S_{t}\right)>D \wedge \max _{0 \leq t \leq T}\left(S_{t}\right) \geq U \wedge S_{T}<X_{1}$ & $n \cdot\left(S_{T}+X_{2}-X_{3}-p_{1 B D I}-p_{2 B U I}+p_{3 S}\right)$ & $n \cdot\left(2 S_{T}-X_{3}-p_{1 B D I}-p_{2 B U O}+p_{3 S}\right)$ \\
\hdashline $\min _{0 \leq t \leq T}\left(S_{t}\right) \leq D \wedge \max _{0 \leq t \leq T}\left(S_{t}\right) \geq U \wedge S_{T}<X_{1}$ & $n \cdot\left(X_{1}+X_{2}-X_{3}-p_{1 B D I}-p_{2 B U I}+p_{3 S}\right)$ & $n \cdot\left(S_{T}+X_{1}-X_{3}-p_{1 B D I}-p_{2 B U O}+p_{3 S}\right)$ \\
$\max _{0 \leq t \leq T}\left(S_{t}\right)<U \wedge X_{1} \leq S_{T}<X_{2}$ & $n \cdot\left(2 S_{T}-X_{3}-p_{1 B D I}-p_{2 B U I}+p_{3 S}\right)$ & $n \cdot\left(S_{T}+X_{2}-X_{3}-p_{1 B D I}-p_{2 B U O}+p_{3 S}\right)$ \\
$\max _{0 \leq t \leq T}\left(S_{t}\right) \geq U \wedge X_{1} \leq S_{T}<X_{2}$ & $n \cdot\left(S_{T}+X_{2}-X_{3}-p_{1 B D I}-p_{2 B U I}+p_{3 S}\right)$ & $n \cdot\left(2 S_{T}-X_{3}-p_{1 B D I}-p_{2 B U O}+p_{3 S}\right)$ \\
$X_{2} \leq S_{T}<X_{3}$ & $n \cdot\left(2 S_{T}-X_{3}-p_{1 B D I}-p_{2 B U I}+p_{3 S}\right)$ & $n \cdot\left(2 S_{T}-X_{3}-p_{1 B D I}-p_{2 B U O}+p_{3 S}\right)$ \\
$S_{T} \geq X_{3}$ & $n \cdot\left(S_{T}-p_{1 B D I}-p_{2 B U I}+p_{3 S}\right)$ & $n \cdot\left(S_{T}-p_{1 B D I}-p_{2 B U O}+p_{3 S}\right)$ \\
\hline
\end{tabular}

Table 5. Final hedged selling prices using Short Put Ladder option strategy_4

\begin{tabular}{|c|c|c|}
\hline Stock price range & Final hedged selling price_4A & Final hedged selling price_4B \\
\hline $\min _{0 \leq t \leq T}\left(S_{t}\right)>D \wedge \max _{0 \leq t \leq T}\left(S_{t}\right)<U \wedge S_{T}<X_{1}$ & $n \cdot\left(S_{T}-p_{1 B D I}-p_{2 B U I}+p_{3 S D I}\right)$ & $n \cdot\left(X_{2}-p_{1 B D I}-p_{2 B U O}+p_{3 S D I}\right)$ \\
\hline $\min _{0 \leq t \leq T}\left(S_{t}\right) \leq D \wedge \max _{0 \leq t \leq T}\left(S_{t}\right)<U \wedge S_{T}<X_{1}$ & $n \cdot\left(S_{T}+X_{1}-X_{3}-p_{1 B D I}-p_{2 B U I}+p_{3 S D I}\right)$ & $n \cdot\left(X_{1}+X_{2}-X_{3}-p_{1 B D I}-p_{2 B U O}+p_{3 S D I}\right.$ \\
\hline $\min _{0 \leq t \leq T}\left(S_{t}\right)>D \wedge \max _{0 \leq t \leq T}\left(S_{t}\right) \geq U \wedge S_{T}<X_{1}$ & $n \cdot\left(X_{2}-p_{1 B D I}-p_{2 B U I}+p_{3 S D I}\right)$ & $n \cdot\left(S_{T}-p_{1 B D I}-p_{2 B U O}+p_{3 S D I}\right)$ \\
\hline $\min _{0 \leq t \leq T}\left(S_{t}\right) \leq D \wedge \max _{0 \leq t \leq T}\left(S_{t}\right) \geq U \wedge S_{T}<X_{1}$ & $n \cdot\left(X_{1}+X_{2}-X_{3}-p_{1 B D I}-p_{2 B U I}+p_{3 S D I}\right)$ & $n \cdot\left(S_{T}+X_{1}-X_{3}-p_{1 B D I}-p_{2 B U O}+p_{3 S D I}\right)$ \\
\hline $\min _{0 \leq t \leq T}\left(S_{t}\right)>D \wedge \max _{0 \leq t \leq T}\left(S_{t}\right)<U \wedge X_{1} \leq S_{T}<X_{2}$ & $n \cdot\left(S_{T}-p_{1 B D I}-p_{2 B U I}+p_{3 S D I}\right)$ & $n \cdot\left(X_{2}-p_{1 B D I}-p_{2 B U O}+p_{3 S D I}\right)$ \\
\hline $\min _{0 \leq t \leq T}\left(S_{t}\right) \leq D \wedge \max _{0 \leq t \leq T}\left(S_{t}\right)<U \wedge X_{1} \leq S_{T}<X_{2}$ & $n \cdot\left(2 S_{T}-X_{3}-p_{1 B D I}-p_{2 B U I}+p_{3 S D I}\right)$ & $n \cdot\left(S_{T}+X_{2}-X_{3}-p_{1 B D I}-p_{2 B U O}+p_{3 S D I}\right)$ \\
\hline $\min _{0 \leq t \leq T}\left(S_{t}\right)>D \wedge \max _{0 \leq t \leq T}\left(S_{t}\right) \geq U \wedge X_{1} \leq S_{T}<X_{2}$ & $n \cdot\left(X_{2}-p_{1 B D I}-p_{2 B U I}+p_{3 S D I}\right)$ & $n \cdot\left(S_{T}-p_{1 B D I}-p_{2 B U O}+p_{3 S D I}\right)$ \\
\hline $\min _{0 \leq t \leq T}\left(S_{t}\right) \leq D \wedge \max _{0 \leq t \leq T}\left(S_{t}\right) \geq U \wedge X_{1} \leq S_{T}<X_{2}$ & $n \cdot\left(S_{T}+X_{2}-X_{3}-p_{1 B D I}-p_{2 B U I}+p_{3 S D I}\right)$ & $n \cdot\left(2 S_{T}-X_{3}-p_{1 B D I}-p_{2 B U O}+p_{3 S D I}\right)$ \\
\hline $\min _{0 \leq t \leq T}\left(S_{t}\right)>D \wedge X_{2} \leq S_{T}<X_{3}$ & $n \cdot\left(S_{T}-p_{1 B D I}-p_{2 B U I}+p_{3 S D I}\right)$ & $n \cdot\left(S_{T}-p_{1 B D I}-p_{2 B U O}+p_{3 S D I}\right)$ \\
\hline $\min _{0 \leq t \leq T}\left(S_{t}\right) \leq D \wedge X_{2} \leq S_{T}<X_{3}$ & $n \cdot\left(2 S_{T}-X_{3}-p_{1 B D I}-p_{2 B U I}+p_{3 S D I}\right)$ & $n \cdot\left(2 S_{T}-X_{3}-p_{1 B D I}-p_{2 B U I}+p_{3 S D I}\right)$ \\
\hline$S_{T} \geq X_{3}$ & $n \cdot\left(S_{T}-p_{1 B D I}-p_{2 B U I}+p_{3 S D I}\right)$ & $n \cdot\left(S_{T}-p_{1 B D I}-p_{2 B U O}+p_{3 S D I}\right)$ \\
\hline
\end{tabular}

\section{ANALYSIS OF THE RESULTS}

In the following part, our proposed hedging techniques are applied in equity sector using the exchange-traded funds (ETFs), specifically, SPDR S\&P 500 ETF (referred SPY). SPY tracks a market cap-weighted index of US large and midcap shares selected by the S\&P Committee. We choose SPY fund due to its size in this category. It is the best-recognized and oldest ETF in USA. Let us suppose that the firm has bought 100 shares of SPDR S\&P 500 ETF (SPY) at USD 283.60 per share on August 3, 2018. Hence, the firm's total investment here is USD 28,360. After some time, the firm realizes that it wants to sell these shares at the end of December 2020 but is worried about the price drop over the period. The firm uses SPL strategy mentioned above and created by vanilla and barrier options to secure the minimum selling price in December 2020. The traded amount of shares is 100 pieces. In addition, the option strategy has to meet the zero-cost condition according 
to relation (1). That is why we exclude all variants that do not meet this condition from our observations. To simplify, we do not consider any transaction costs and trading constraints. Only hedging techniques, which fulfill the abovementioned requirements, are presented in the next part.

\subsection{Data description}

The shares of SPY are traded at USD 283.60 per share on August 3, 2018. Table 6 presents the basic key hedging information.

Table 6. Key hedging information

Source: Yahoo Finance (2018)

\begin{tabular}{|c|c|c|c|c|c|}
\hline $\begin{array}{c}\text { Underlying } \\
\text { asset }\end{array}$ & $\begin{array}{c}\text { Issue } \\
\text { date }\end{array}$ & $\begin{array}{l}\text { Issue } \\
\text { price }\end{array}$ & $\begin{array}{c}\text { Maturity } \\
\text { date }\end{array}$ & Multiplier & $\begin{array}{c}\text { Dividend } \\
\text { yield }\end{array}$ \\
\hline $\begin{array}{l}\text { SPDR S\&P } \\
500 \text { ETF }\end{array}$ & $\begin{array}{c}\text { August 3, } \\
2018\end{array}$ & 283.60 & $\begin{array}{c}\text { December } \\
18,2020\end{array}$ & $1: 10$ & $1.73 \%$ \\
\hline
\end{tabular}

The dataset consists of 34 vanilla put options, which are traded in the market and obtained from Yahoo Finance (2018), and 165 European DI/DO/UI/UO barrier options. The UA's price and option premiums are in USD. Barrier options are calculated according to Haug model (2007) in statistical program $\mathrm{R}$ based on the function (2). The input parameters are UA's spot price (USD 283.60), time to maturity (2.38 years, i.e., hedging period from August 3, 2018 to December 18,2020 ), interest rate $2.69 \%$ (gained from treasury.gov), dividend yield 1.73\% (gained from google.com/finance) and historical volatility 10.8\% (analyzed for period March 17, 2016 - August 2, 2018). Table 7 presents the selected European put option premiums for classic vanilla and barrier options (barriers USD 240 and USD 330).

Table 7. European put/put barrier option premiums with barrier levels 240 and 330 on August 3, 2018

Source: Finance Yahoo (2018), own calculations in statistical program R.

\begin{tabular}{|c|c|c|c|c|c|c|}
\hline $\begin{array}{c}\text { Implied } \\
\text { volatility } \\
(\%)\end{array}$ & Strike & Put & $\begin{array}{l}\text { Put }_{\text {DI }} \\
(240)\end{array}$ & $\begin{array}{l}\text { Put }_{\text {Do }} \\
(240)\end{array}$ & $\begin{array}{l}\text { Put }_{\mathrm{UI}} \\
\text { (330) }\end{array}$ & $\begin{array}{l}\text { Put }_{\text {uo }} \\
\text { (330) }\end{array}$ \\
\hline 1.56 & 250 & 13.91 & 4.22 & 0.04 & 0.05 & 4.21 \\
\hline 16.65 & 260 & 16.91 & 6.23 & 0.33 & 0.12 & 6.45 \\
\hline 15.80 & 270 & 20.00 & 8.52 & 1.07 & 0.24 & 9.35 \\
\hline 0.20 & 280 & 22.85 & 11.00 & 2.40 & 0.44 & 12.95 \\
\hline 12.46 & 290 & 26.59 & 13.61 & 4.39 & 0.78 & 17.21 \\
\hline 12.94 & 300 & 31.18 & 16.29 & 7.07 & 1.31 & 22.05 \\
\hline 13.26 & 310 & 37.10 & 19.03 & 10.41 & 2.10 & 27.35 \\
\hline 13.67 & 320 & 44.90 & 21.80 & 14.37 & 3.21 & 32.97 \\
\hline
\end{tabular}

Notes: Option premiums are in USD.
The strike prices of vanilla $\mathrm{CO}$ are considered in the range of 200-370. The barrier levels are selected by authors. In our case, the lower barriers of DI/DO PO are in the range of 230-260 and upper barriers of UI/UO PO are in the range of 290-350, all in multiplies of 10 . Based on the dataset, the exercise prices are:

1. $X_{1}=250, X_{2}=260$ and $X_{3}=320$;

2. $X_{1}=260, X_{2}=265$ and $X_{3}=310$;

3. $X_{1}=270, X_{2}=280$ and $X_{3}=320$;

4. $X_{1}=280, X_{2}=290$ and $X_{3}=340$.

Five thousand seventy-two hedging variants (588 variants with vanilla options and 4,484 variants with only barrier options) in total are proposed and analyzed. The highest strike price $X_{3}$ should be always set above the actual UA's price So. In this paper, we present only the selected variants, which fulfilk the condition of the zero-cost strategy. To simplify the results interpretation, the same barrier for UI/UO options (the level USD 330) and for DI/DO options (the level USD 240) are used.

\subsection{Results and discussion}

Hedging tools introduced have secured a minimum acceptable selling price of the UA, where the zero-cost option condition is preferred. The SPY actual spot price is 283.60 USD per share on August 3, 2018 and there is the expected SPY price drop in December 2020.

According to the first hedging variant, we will buy 100 DI PO with the exercise price 250, the barrier level 240, the premium 4.22 per option and, simultaneously, we will buy 100 PO with the exercise price 260 , the premium 16.91 per option and sell 100 put options with the exercise price 320 and the premium 44.90 per option. This variant is the simplest from all analyzed variants. Table 8 lists the final selling prices in USD in case of different future SPY price scenarios, while cash market price is $100 \cdot S_{T}$.

From Table 8 and Figure 1, where there is the comparison of cash market price with the final selling 
Table 8. Final selling prices using Short Put Ladder option strategy_1A

Source: Own calculations.

\begin{tabular}{|c|c|c|c|c|c|}
\hline \multirow[t]{2}{*}{ SPY price range } & \multirow[t]{2}{*}{ Final SPY selling price } & \multicolumn{2}{|c|}{$\begin{array}{l}\text { Final selling price of SPY per } \\
\text { share }\end{array}$} & \multicolumn{2}{|c|}{$\begin{array}{c}\text { Final hedged selling price } \\
\text { per share }\end{array}$} \\
\hline & & $\min$ & $\max$ & $\min$ & $\max$ \\
\hline $\min _{0 \leq t \leq T}\left(S_{t}\right)>240 \wedge S_{T}<250$ & $100 S_{T}-3,623.30$ & 24,000 & 25,000 & $20,376.75$ & $21,376.75$ \\
\hline $\min _{0 \leq t \leq T}\left(S_{t}\right) \leq 240 \wedge S_{T}<250$ & $21,376.80$ & 0 & 25,000 & $21,376.75$ & $21,376.75$ \\
\hline $250 \leq S_{T}<260$ & $100 S_{T}-3,623.30$ & 25,000 & 26,000 & $21,376.75$ & $22,376.75$ \\
\hline $260 \leq S_{T}<320$ & $200 S_{T}-29,623.25$ & 26,000 & 32,000 & $22,376.75$ & $34,376.75$ \\
\hline$S_{T} \geq 320$ & $100 S_{T}+2,376.75$ & 32,000 & $\infty$ & $34,376.75$ & $\infty$ \\
\hline
\end{tabular}

price at various SPY price scenarios development, the following conclusions are formulated:

- if the spot price of SPY shares during time to maturity does not reach the barrier level USD 240 and is lower than USD 296.23, then, the unsecured position is better than the hedged one, otherwise, the hedged variant is better;

- on the other hand, in case of reaching the barrier level of USD 240 during time to maturity and SPY price is below USD 250, the hedged position secures constant selling price of USD 213.76 per share.

If we consider buying the put option with the strike price $X_{2}$ equals USD 280 (paid option pre-

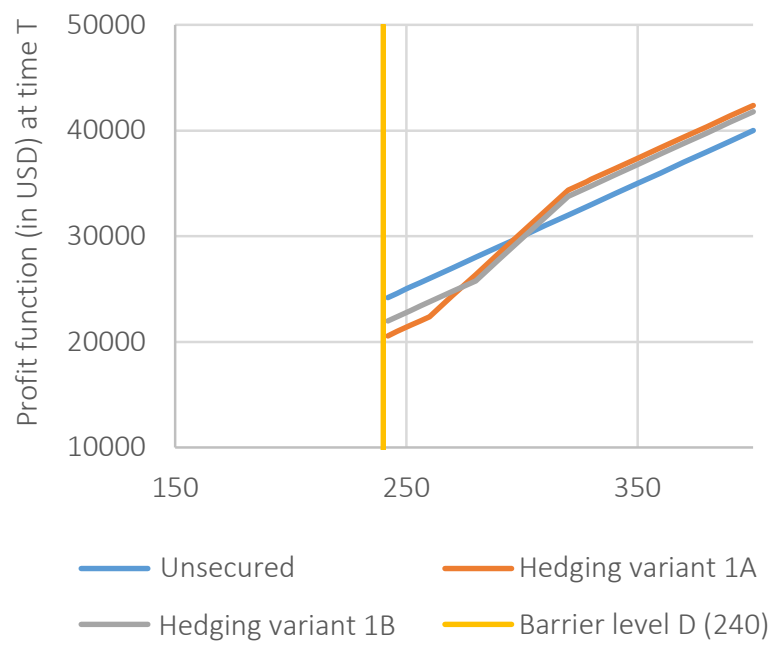

(a) mium is USD 22.85 - variant $1 \mathrm{~B}$ ) and the other parameters would not change against variant $1 \mathrm{~A}$, then, the profit from this variant is lower than from the previous one. However, if we expect a strong drop in the SPY price, then, variant $1 \mathrm{~B}$ is better, which is due to the higher strike price $X_{2}$, when we secure minimum selling price at USD $22,782.80$. The comparison of variants $1 \mathrm{~A}, 1 \mathrm{~B}$, and unsecured position is in Figure 1.

Other hedging variants are created as combinations of barrier options. We trade 100 options and all is denominated in USD. Table 9 shows the specific proposals of individual parameters with option premiums.

In the same way, we could suggest other combi-

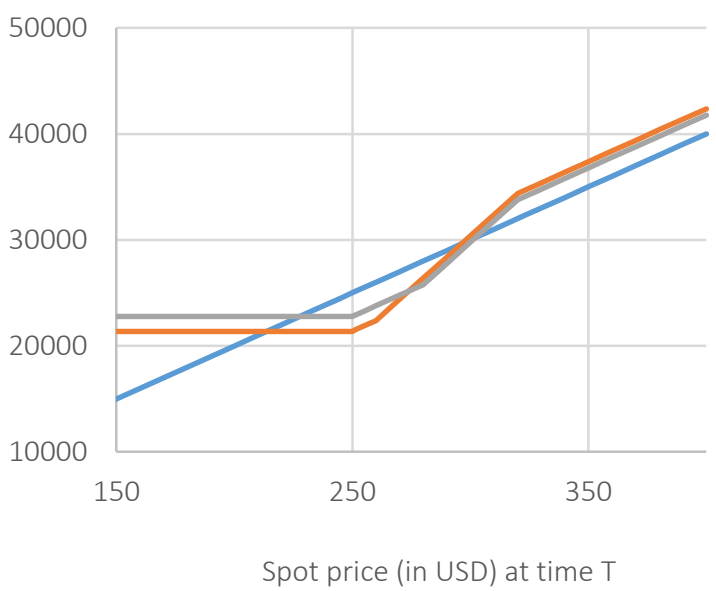

(b)

Note: (a) Barrier level $D$ is not reached during time to maturity, (b) Barrier level $D$ is reached during time to maturity.

Figure 1. Comparison of the variants $1 \mathrm{~A}$ and $1 \mathrm{~B}$ with the unsecured position 
Table 9. Parameters of analyzed hedging variants with barrier options

Source: Own design.

\begin{tabular}{|c|c|c|c|}
\hline Position & Hedging variant $2 \mathrm{~A}$ & Hedging variant $3 \mathrm{~A}$ & Hedging variant 3B \\
\hline Buy & \multicolumn{3}{|c|}{$\mathrm{DIPO}\left(X_{1}=250, D=240\right), p_{1}=4.22$} \\
\hline Buy & DI PO $\left(X_{2}=260, D=240\right), p_{2}=6.23$ & $\mathrm{UIPO}\left(X_{2}=260, U=330\right), p_{2}=0.12$ & UO PO $\left(X_{2}=260, U=330\right), p_{2}=6.45$ \\
\hline Sell & \multicolumn{3}{|c|}{$\mathrm{PO}\left(X_{3}=330\right), p_{3}=44.9$} \\
\hline Position & \multicolumn{2}{|c|}{ Hedging variant $4 \mathrm{~A}$} & Hedging variant 4B \\
\hline Buy & \multicolumn{3}{|c|}{$\mathrm{DIPO}\left(X_{1}=250, D=240\right), p_{1}=4.22$} \\
\hline Buy & \multicolumn{2}{|c|}{$\mathrm{UIPO}\left(X_{2}=260, U=330\right), p_{2}=0.33$} & UO PO $\left(X_{2}=260, U=330\right), p_{2}=6.45$ \\
\hline Sell & \multicolumn{3}{|c|}{$\mathrm{DIPO}\left(X_{3}=320, D=240\right), p_{3}=21.80$} \\
\hline
\end{tabular}

Notes: DI - down in, DO - down out, UI - up in, UO - up out, PO - put option, $X$ - strike price, $D$ - down barrier, $U$ - up barrier, $p$-option premium.

nations of options, where the selected parameters would change the amount of the option premium. The comparison of all analyzed hedging variants (data from Table 9) at various SPY price scenarios development are shown in Table 10 with more detailed illustration of selected hedging variants provided. The results from Table 10 show that choosing the best variant depends on the investor's ex- pectations regarding the UA's price development. In case of strong volatility where SPY drops under $D$ and rises above $U$, the best variant is $3 \mathrm{~A}$ with securing the highest selling price of USD 230.56 per share. However, if the SPY drops only slightly ( $D$ is not reached) but rises above $U$ barrier, then, $4 \mathrm{~A}$ variant secures the highest selling price of USD 277.25 per share.

Table 10. Comparison of the hedging techniques $2 \mathrm{~A}, 3 \mathrm{~A}-3 \mathrm{~B}$ and $4 \mathrm{~A}-4 \mathrm{~B}$

Source: Own calculations.

\begin{tabular}{|c|c|c|c|c|c|}
\hline SPY price range & $\begin{array}{l}\text { Final selling } \\
\text { price_2A }\end{array}$ & $\begin{array}{c}\text { Final selling } \\
\text { price_3A }\end{array}$ & $\begin{array}{l}\text { Final selling } \\
\text { price_3B }\end{array}$ & $\begin{array}{c}\text { Final selling } \\
\text { price_4A }\end{array}$ & $\begin{array}{l}\text { Final selling } \\
\text { price_4B }\end{array}$ \\
\hline $\min _{0 \leq t \leq T}\left(S_{t}\right)>240 \wedge S_{T}<250$ & $\begin{array}{c}200 S_{J} \\
-28,555.22\end{array}$ & - & - & - & - \\
\hline $\min _{0 \leq t \leq T}\left(S_{t}\right) \leq 240 \wedge S_{T}<250$ & $22,444.8$ & - & - & - & - \\
\hline $\min _{0 \leq t \leq T}\left(S_{t}\right)>240 \wedge \max _{0 \leq t \leq T}\left(S_{t}\right)<330 \wedge S_{T}<250$ & - & $\begin{array}{l}200 S_{T} \\
-27,944.06\end{array}$ & $\begin{array}{c}100 S_{T} \\
-2,576.77\end{array}$ & $100 S_{T}+1,724.8$ & $27,134.6$ \\
\hline $\min _{0 \leq t \leq T}\left(S_{t}\right) \leq 240 \wedge \max _{0 \leq t \leq T}\left(S_{t}\right)<330 \wedge S_{T}<250$ & - & $\begin{array}{c}100 S_{T} \\
-2,944.06\end{array}$ & $22,423.2$ & $100 S_{T}-5,275.2$ & $20,134.6$ \\
\hline $\min _{0 \leq t \leq T}\left(S_{t}\right)>240 \wedge \max _{0 \leq t \leq T}\left(S_{t}\right) \geq 330 \wedge S_{T}<250$ & - & $\begin{array}{c}100 S_{T} \\
-1,944.06\end{array}$ & $\begin{array}{c}200 S_{T} \\
-28,576.77\end{array}$ & $27,724.8$ & $\begin{array}{c}100 S_{T^{+}}^{+} \\
1,134.57\end{array}$ \\
\hline $\min _{0 \leq t \leq T}\left(S_{t}\right) \leq 240 \wedge \max _{0 \leq t \leq T}\left(S_{t}\right) \geq 330 \wedge S_{T}<250$ & - & $23,055.9$ & $\begin{array}{c}100 S_{T}^{T} \\
-3,576^{\top} .77\end{array}$ & $20,724.8$ & $\begin{array}{c}100 S_{T}^{T} \\
-5,865.43\end{array}$ \\
\hline $\min _{0 \leq t \leq T}\left(S_{t}\right)>240 \wedge 250 \leq S_{T}<260$ & $\begin{array}{c}200 S_{T} \\
-28,555.22\end{array}$ & - & - & - & - \\
\hline $\min _{0 \leq t \leq T}\left(S_{t}\right) \leq 240 \wedge 250 \leq S_{T}<260$ & $\begin{array}{l}100 S_{T} \\
-2,555.22\end{array}$ & - & - & - & - \\
\hline $\min _{0 \leq t \leq T}\left(S_{t}\right)>240 \wedge \max _{0 \leq t \leq T}\left(S_{t}\right)<330 \wedge 250 \leq S_{T}<260$ & - & - & - & $100 S_{T}+1,724.8$ & $27,134.6$ \\
\hline $\min _{0 \leq t \leq T}\left(S_{t}\right) \leq 240 \wedge \max _{0 \leq t \leq T}\left(S_{t}\right)<330 \wedge 250 \leq S_{T}<260$ & - & - & - & $\begin{array}{c}200 S_{T} \\
-30,275.2\end{array}$ & $\begin{array}{c}100 S_{T} \\
-4,865.43\end{array}$ \\
\hline $\min _{0 \leq t \leq T}\left(S_{t}\right)>240 \wedge \max _{0 \leq t \leq T}\left(S_{t}\right) \geq 330 \wedge 250 \leq S_{T}<260$ & - & - & - & $27,724.8$ & $\begin{array}{c}100 S_{T}^{+} \\
1,134.57\end{array}$ \\
\hline $\min _{0 \leq t \leq T}\left(S_{t}\right) \leq 240 \wedge \max _{0 \leq t \leq T}\left(S_{t}\right) \geq 330 \wedge 250 \leq S_{T}<260$ & - & - & - & $100 S_{T}-4,275.2$ & $\begin{array}{l}200 S_{I} \\
-30,865.43\end{array}$ \\
\hline $\max _{0 \leq t \leq T}\left(S_{t}\right)<330 \wedge 250 \leq S_{T}<260$ & - & $\begin{array}{c}200 S_{T} \\
-27,944.06\end{array}$ & $\begin{array}{c}100 S_{T} \\
-2,576.77\end{array}$ & - & - \\
\hline $\max _{0 \leq t \leq T}\left(S_{t}\right) \geq 330 \wedge 250 \leq S_{T}<260$ & - & $\begin{array}{c}100 S_{T} \\
-1,944.06\end{array}$ & $\begin{array}{c}200 S_{T} \\
-28,576.77\end{array}$ & - & - \\
\hline $\min _{0 \leq t \leq T}\left(S_{t}\right)>240 \wedge 260 \leq S_{T}<320$ & - & - & - & $100 S_{T}+1,724.8$ & $\begin{array}{c}100 S_{T}^{+} \\
1,134.57\end{array}$ \\
\hline $\min _{0 \leq t \leq T}\left(S_{t}\right) \leq 240 \wedge 260 \leq S_{T}<320$ & - & - & - & $\begin{array}{c}200 S_{T} \\
-30,275.2\end{array}$ & $\begin{array}{c}200 S_{T} \\
-30,865.43\end{array}$ \\
\hline $260 \leq S_{T}<320$ & $\begin{array}{r}200 S_{T} \\
-28,555.22\end{array}$ & $\begin{array}{r}200 S_{T} \\
-27,944.06\end{array}$ & $\begin{array}{c}200 S_{T} \\
-28,576.77\end{array}$ & - & - \\
\hline$S_{T} \geq 320$ & $\begin{array}{l}100 S_{T}^{+} \\
3,444.78 \\
\end{array}$ & $\begin{aligned} & 100 S_{T} \\
&-4,055.94 \\
&\end{aligned}$ & $\begin{array}{l}100 S^{+} \\
3,423.23 \\
\end{array}$ & $100 S_{T}+1,724.8$ & $\begin{array}{l}100 S^{+} \\
1,134.57\end{array}$ \\
\hline
\end{tabular}




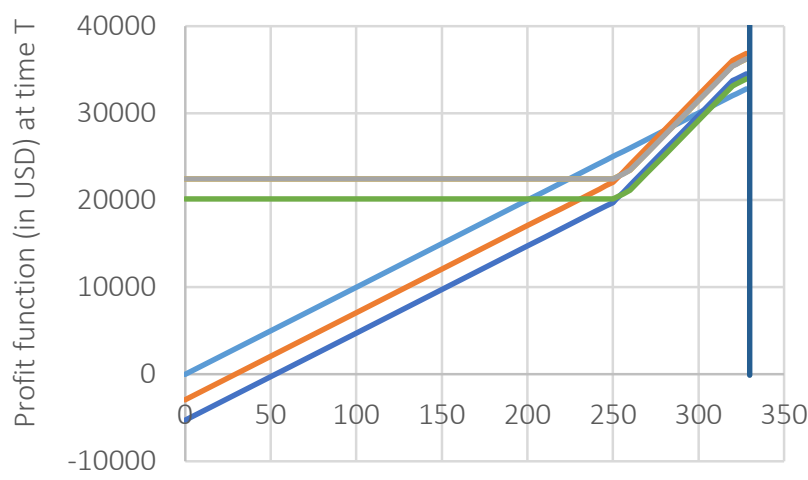

(a)

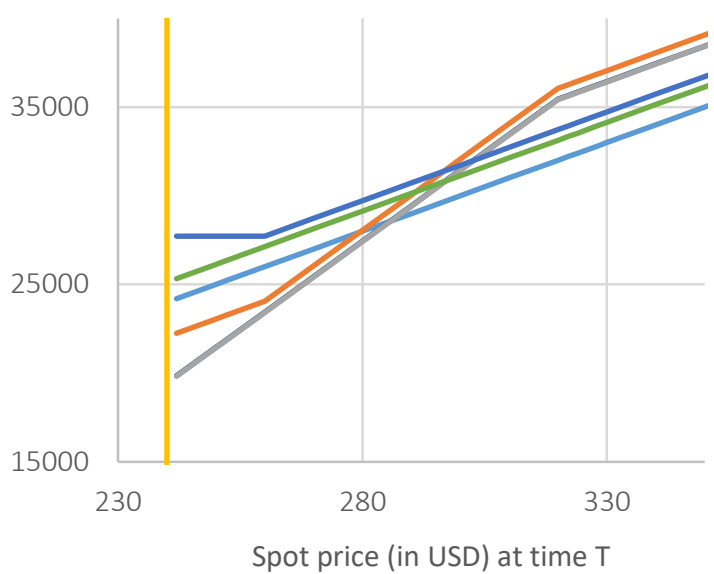

(b)

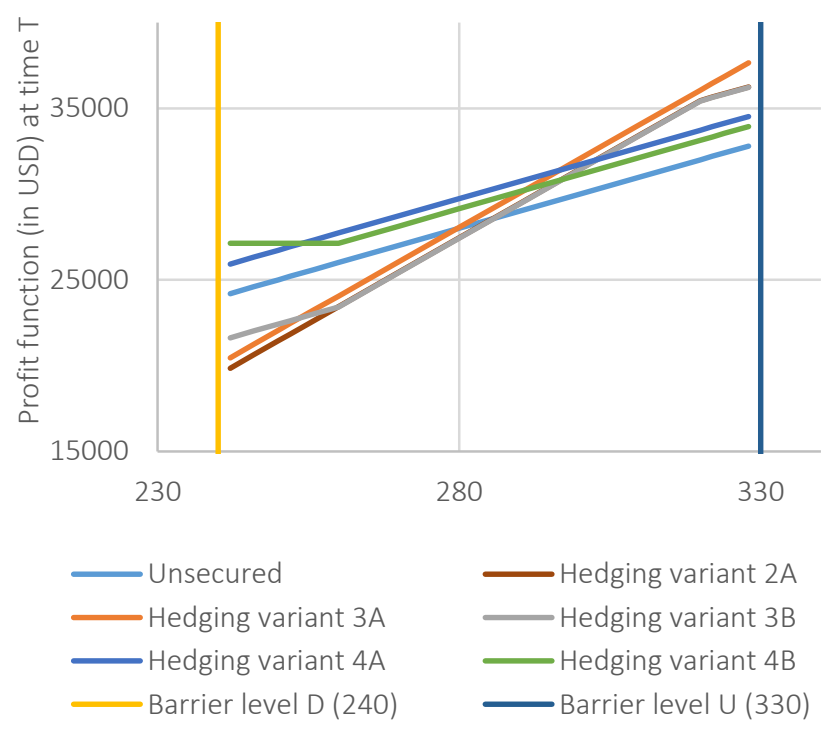

(c)

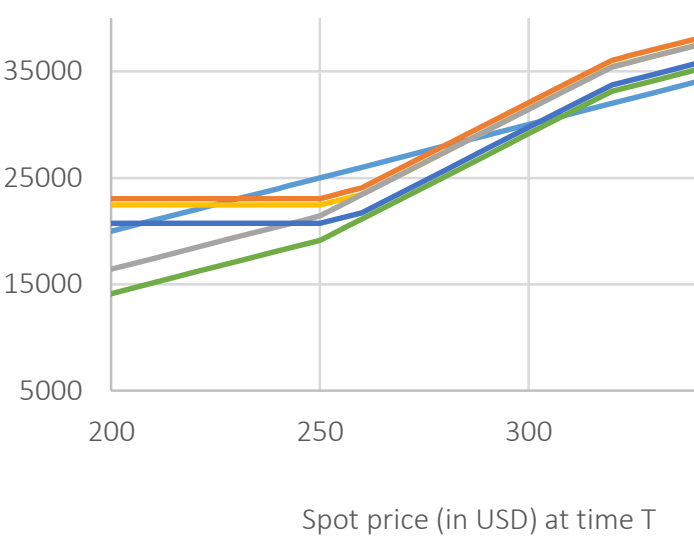

(d)

Note: (a) Barrier level $\mathrm{D}$ is reached and $\mathrm{U}$ is not reached during time to maturity; (b) Barrier level $\mathrm{D}$ is not reached and $\mathrm{U}$ is reached during time to maturity; (c) Barrier levels D and $U$ are not reached during time to maturity; (d) Barrier levels D and $U$ are reached during time to maturity.

\section{Figure 2. Comparison of the selected analyzed hedging techniques}

Graphical comparison of selected variants is illustrated in Figure 2.

Let us look at Table 10 and Figure 2, where the following conclusions are valid:

- if both of barrier levels (D 240 USD and U 330 USD) are not reached during the time to maturity, then, $4 \mathrm{~A}$ variant is better in the interval $<254.10 ; 296.69>$ at the maturity date, otherwise, up to lower barrier D $4 \mathrm{~B}$ variant with the fixed income USD 271.35 per share is better and up to higher barrier $\mathrm{U} 3 \mathrm{~A}$ variant is better; if the SPY spot price during the time to maturity drops under $\mathrm{D}$ and does not raise above $\mathrm{U}$ and is within an interval $<224.45 ; 279.44>$ at the maturity date, the unsecured position is better, otherwise, $3 \mathrm{~A}$ variant secures better results but the higher income is limited up to upper barrier USD 330;

- for the third case, if $\mathrm{D}$ is not reached and $\mathrm{U}$ is reached during the time to maturity, the variant $4 \mathrm{~A}$ secures higher income in interval $<240$, $296.69>$ at the maturity date. Otherwise, the variant $3 \mathrm{~A}$ is better up to the endlessly; 
Table 11. An overview of the results from our analysis

\begin{tabular}{|c|c|c|c|c|}
\hline Direction of UA & $\begin{array}{c}D \text { reached } \\
U \text { unreached }\end{array}$ & $\begin{array}{l}D \text { unreached } \\
U \text { unreached }\end{array}$ & $\begin{array}{c}D \text { unreached } \\
U \text { reached }\end{array}$ & $\begin{array}{l}D \text { reached } \\
U \text { reached }\end{array}$ \\
\hline$\downarrow \downarrow$ & $2 \mathrm{~A}, 3 \mathrm{~B}, 3 \mathrm{~A}$ & - & - & $3 A$ \\
\hline$\downarrow$ & Unsecured & $4 \mathrm{~A}, 4 \mathrm{~B}$ & $4 \mathrm{~A}, 4 \mathrm{~B}$ & Unsecured \\
\hline $\mathrm{S}$ & Unsecured, $3 \mathrm{~A}$ & $3 A, 4 A, 4 B$ & $3 A, 4 A, 4 B$ & $3 A$ \\
\hline$\uparrow$ & $2 A, 3 A, 3 B$ & $2 A, 3 A, 3 B, 4 A, 4 B$ & $2 A, 3 A, 3 B, 4 A, 4 B$ & $2 A, 3 A, 3 B$ \\
\hline$\uparrow \uparrow$ & - & - & $2 A, 3 A, 3 B, 4 A, 4 B$ & $2 A, 3 A, 3 B, 4 A, 4 B$ \\
\hline
\end{tabular}

Notes: $D$ - down barrier, $U$ - up barrier, UA - underlying asset, $\downarrow \downarrow-$ strong drop, $\downarrow$ - slightly drop, S - stagnation, $\uparrow-$ slightly rising, $\uparrow \uparrow-$ strong rising.

- if the both of barrier levels are reached, the variant $3 \mathrm{~A}$ is better up to spot price USD 230.56 and above USD 279.44, otherwise, the unsecured variant is better.

All hedging techniques using barrier options are very interesting in a strong or slightly price drop. Barrier option is always cheaper than classic vanilla option, according to Taleb (1997). Therefore, the hedger's choice of the barrier options in the hedging techniques depends mainly on the expectations of the UA's price development. An overview of the results of our analysis is showed in Table 11, where the strategies that provide a higher selling price versus the unsecured position for each SPY price development scenario are introduced. In our expected SPY price scenario, i.e., the lower barrier $D$ is reached during the time to maturity but the upper barrier $U$ is not reached, and the SPY price at the maturity date is lower than 250 , the variants $2 \mathrm{~A}$ and $3 \mathrm{~B}$ are the best in comparison to others, as the minimum selling prices in the values of USD 224.45 and 224.23 per share are secured.
The findings of our analysis show that hedgers can choose between knock-in and knockout barrier options based on zero-cost option strategy. Zero-cost option strategy is secured only with the right combination of the exercise prices, while $X_{3}$ should be set above $S_{0}$. If strong drop/increase is expected, we select those knock-in options, which are activated after reaching the barrier level. Otherwise, if we expect only moderate drop/increase, we choose those knock-out options, which are deactivated after reaching the barrier level. Finally, some hedging variants are better than the unsecured position for our expected SPY price drop without strong rise of its price above the upper barrier. Therefore, the final decision is at hedger's expectations and willingness to take risks. If the hedger's expectations are not met, he could gain a loss in comparison to the direct position in UA. The results of our research based on barrier options fills a noticeable gap in the field of equity risk management and can contribute to the literature.

\section{CONCLUSION}

Many investors realize that the stock market is a volatile place to invest their money. However, new opportunities in the form of derivatives provide one way of hedging of UA's price. The purpose of the paper was to provide the overview of new techniques (Short Put Ladder strategy), created by barrier options to manage the equity risk. The introduced strategy is used for hedging at the price drop. At the beginning, the literature review and the research methodology were presented. The research on managing the risk using the barrier options has not been carried out in risk management and therefore appears to be unique in this field. Due to this fact, the paper contributes to the recent literature.

The main aim of our research was to analyze and compare different ways of Short Put Ladder strategy creation using the barrier options and their application in equity market, namely, SPDR S\&P 500 ETF. The primary aim was to choose hedging variants, which fulfil the zero-costs requirements. Our research shows that using the barrier options generates more alternatives for risk management. Based on the mentioned assumptions, we introduced only suitable variants in detailed description, in which various combinations of buying DI put options (the smallest strike price) are used. The numerical examples of 
given hedging variants are presented where the hedger's choice of the barrier options (also level of the strike prices) depends mainly on the expectations of the SPY's price development. The analyzed combinations of options secure certain level of SPY selling price at the maturity date. Other variants are not excluded from our observations. Their income is interesting as well but these results are not presented in the paper. However, the final decision for choosing the combination of the strike prices, down and up barrier levels and types of vanilla/barrier options, is up to the hedger and his expectations about development of the UA's price and the willingness to undertake a risk. These results can be important for firms, individual investors, practitioners, other market participants, and the general public. The main paper's contribution is to emphasize the barrier options as one type of derivative tools, where the payoff structures produce better results for managing the risk in the equity market, as well as in different financial markets.

\section{REFERENCES}

1. Allen, S. L. (2013). Financial risk management, A Practitioner's Guide to Managing Market and Credit Risk (2nd ed.). New Jersey: Wiley \& Sons. Retrieved from vhttps://www.amazon.com/Financial-Risk-Management-Practitioners-Managing/dp/111817545X

2. Amaitiek, O. F. S., Bálint, T., \& Rešovský, M. (2010). The Short Call Ladder strategy and its application in trading and hedging. Acta Montanistica Slovaca, 15(3), 171-182. Retrieved from https:// www.researchgate.net/publication/50934223_The_Short_Call_ Ladder_strategy_and_its_application_in_trading_and_hedging

3. Black, F., \& Scholes, M. (1973). The Pricing of Options and Corporate Liabilities. Journal of Political Economy, 81(3), 637-654. https://doi.org/10.1086/260062

4. Brown, G. W. (2001). Managing foreign exchange risk with derivatives. Journal of Financial Economics, 60(2-3), 401-448. https://doi.org/10.1016/S0304405X(01)00049-6

5. Carol, A. (2008). Market Risk Analysis, Pricing, Hedging and Trading Financial Instruments (Volume III). Chichester: John Wiley \& Sons, Ltd. Retrieved from https://www.amazon.com/Analysis-Pricing-Hedging-FinancialInstruments/dp/0470997893

6. Cohen, G. (2005). The Bible of Options Strategies: The Definitive Guide for Practical Trading Strategies. New Jersey: Pearson Educa- tion, Inc. Retrieved from https:// www.amazon.com/Bible-OptionsStrategies-Definitive-Practical/ $\mathrm{dp} / 0134190165$

7. Deng, S., Elyasiani, E., \& Mao, C. X. (2017). Derivatives-hedging, risk allocation and the cost of debt: Evidence from bank holding companies. The Quarterly Review of Economics and Finance, 65, 114-127. https://doi.org/10.1016/j. qref.2016.06.004

8. Hammoudeh, S., \& McAleer, M. (2013). Risk management and financial derivatives: An overview. The North American Journal of Economics and Finance, 25, 109115. https://doi.org/10.1016/j. najef.2012.06.014

9. Hankins, K. W. (2009). How Do Financial Firms Manage Risk? Unraveling the Interaction of Financial and Operational Hedging. Management Science, 57(12), 2197-2212. https://doi. org/10.1287/mnsc. 1090.1068

10. Harčariková, M. (2018). Managing price risk in the corn market using option strategies. Acta Universitatis agriculturae et silviculturae Mendelianae Brunensis, 66(3), 767-779. https://doi.org/10.11118/actaun201866030767

11. Harčariková, M., \& Šoltés, M. (2016). Risk Management in Energy Sector Using Short Call Ladder Strategy. Montenegrin Journal of Economics, 12(3), 39-54. https://doi.org/10.14254/1800$5845.2016 / 12-3 / 3$
12. Haug, E. G. (2007). The Complete Guide to Option Pricing Formulas (2nd ed.). Hardcover: McGrawHill. Retrieved from https:// www.amazon.com/CompleteGuide-Option-Pricing-Formulas/ dp/0071389970

13. Hirtle, B. (2009). Credit derivatives and bank credit supply. Journal of Financial Intermediation, 18(2), 125-150. https://doi. org/10.1016/j.jfi.2008.08.001

14. Hull, J. C. (2017). Options, Futures and Other Derivatives (8th ed.). New Jersey: Prentice-Hall. Retrieved from https://www.amazon. com/Options-Futures-Other-Derivatives-9th/dp/0133456315

15. Chance, D. M., \& Brooks, R. (2012). An Introduction to Derivatives and Risk Management (9th ed.). South-Western: Cengage Learning.

16. Chorafas, D. N. (2006). Wealth Management Private Banking, Investment Decisions and Structured Financial Products. London: Elsevier Ltd. Retrieved from https:// www.amazon.com/Wealth-Management-Investment-DecisionsStructured/dp/0750668555

17. Iacus, S. M. (2011). Option Pricing and Estimation of Financial Models with $R$. United Kingdom: John Wiley \& Sons, Ltd. Retrieved from https://www.amazon.com/OptionPricing-Estimation-FinancialModels/dp/0470745843

18. Kakushadze, Z., \& Serur, J. A. (2018). 151 Trading Strategies. Switzerland: Palgrave Macmillan. 
Retrieved from https://papers.ssrn. $\mathrm{com} / \mathrm{sol} 3 /$ papers.cfm?abstract_ $\mathrm{id}=3247865$

19. Loss, F. (2012). Optimal Hedging Strategies and Interactions between firms. Journal of economics \& management strategy, 21(1), 79-129. https://doi.org/10.1111/ j.1530-9134.2011.00328.x

20. Merton, R. C. (1973). Theory of rational option pricing. Journal of Economics and Management Science, 4(1), 141-183. https://doi. org $/ 10.2307 / 3003143$

21. Pineda, S., \& Conejo, A. J. (2012). Managing the financial risks of electricity producers using options. Energy Economics, 34(6), 22162227. https://doi.org/10.1016/j. eneco.2012.03.016

22. Rubinstein, M., \& Reiner, E. (1991). Breaking Down the Barriers. Journal of Risk, 4, 28-35. Retrieved from https://www. academia.edu/16585738/Breaking_down_the_barriers
23. Rusnáková, M. (2012). Barrier options and their using in hedging (Dissertation thesis). Košice: Technical University of Košice, Faculty of Economics, Košice, Slovakia.

24. Šoltés, V., \& Amaitiek, O. F. S. (2010). The Short Put Ladder Strategy and its Application in Trading and Hedging. Theory Methodology Practice (TMP), 6(2), 77-85. Retrieved from http:// tmp.gtk.uni-miskolc.hu/volumes/2010/02/TMP_2010_02_11. pdf

25. Šoltés, V., \& Rusnáková, M. (2013). Hedging Against a Price Drop Using the Inverse Vertical Ratio Put Spread Strategy Formed by Barrier Options. Inzinerine Ekonomika - Engineering Economics, 24(1), 18-27. https://doi.org/10.5755/j01. ee.24.1.3505

26. Taleb, N. N. (1997). Dynamic Hedging: Managing Vanilla and Exotic Options. Hardcover: Wiley \& Sons.
27. Terje, A. (2016). Risk assessment and risk management: Review of recent advances on their foundation. European Journal of Operational Research, 253(1), 1-13. https://doi.org/10.1016/j. ejor.2015.12.023

28. Yahoo Finance. (2018). SPDR S\&P 500 ETF (SPY). Retrieved from https://finance.yahoo.com/quote/ SPY/options? $\mathrm{p}=$ SPY (accessed on August 8, 2018).

29. Zhang, P. G. (1998). Exotic options: A Guide to Second Generation Options (2nd ed.). Singapore: World Scientific Publishing. Retrieved from https://www.amazon.com/ Exotic-Options-Guide-SecondGeneration/dp/9810235216

30. Zhou, V. Y., \& Wang, P. (2013). Managing foreign exchange risk with derivatives in UK nonfinancial firms. International Review of Financial Analysis, 29, 294-302. https://doi.org/10.1016/j. irfa.2012.07.005 